\title{
Comparison of various anthropometric indices in predicting abdominal obesity in Chinese children: a cross-sectional study
}

\author{
Gengdong Chen ${ }^{1}$, Huanchang Yan², Yuting Hao², Shiksha Shrestha², Jue Wang², Yan Li², Yuanhuan Wei²,
} Jialiang Pan $^{3^{*}}$ and Zheqing Zhang ${ }^{2^{*}}$ (D)

\begin{abstract}
Background: Former evidence regarding reference values of abdominal fat percentage (AFP) and optimal anthropometric indicators in predicting abdominal obesity measured by dual-energy $X$-ray absorptiometry (DXA) scan in Chinese children were scarce.

Methods: A total of 452 Chinese children aged 6-9 years were included in this cross-sectional study. Abdominal fat and lean mass were measured by a DXA scan, and AFP were calculated. Anthropometric indicators including body mass index (BMI), chest circumference (CC), waist circumference (WC) and hip circumference (HC) were measured, waist-to-hip ratio (WHR), waist-to-height ratio (WHtR) was also calculated.
\end{abstract}

Results: By defining abdominal obesity as those with an AFP $\geq 85$ th percentile, the cutoffs values are 24.80, 30.29, 31.58, $31.86 \%$ in boys, and 25.02, 30.32, 31.66, 31.79\% in girls, for children aged 6, 7, 8, and 9 years old, respectively. All anthropometric indicators were independently and positively associated with AFP ( $P$ all $<0.01)$. In girls, BMI was found to be the optimal predictors of childhood abdominal obesity. The values of area under curves (AUCs) were significantly higher $(P$ all $<0.05)$ than other anthropometric indicators, except for WHtR (AUCs value: 0.886). However, in boys, WHtR instead of BMl, provided the largest AUCs value (0.922) in predicting abdominal obesity, followed by BMl ((AUCS value: 0.913).

Conclusion: This study provides reference values of AFP measured by DXA in Chinese children aged 6-9years. $\mathrm{BMI}$ and $\mathrm{WHtR}$ tend to be the optimal anthropometric indicators in predicting abdominal obesity in Chinese girls and boys, respectively.

Keywords: Abdominal obesity, Fat percentage, Anthropometric indicators, Children, Chinese

\section{Background}

Childhood obesity has been increasing with an alarming rate globally and becoming one of the crucial medical issues threatening public health [1]. Extensive evidence indicates that obesity, especially abdominal obesity during childhood was associated with increased risks of metabolism syndrome [2], diabetes [3], and cardiovascular

\footnotetext{
*Correspondence: panjialiang707@163.com; zzqaa501@smu.edu.cn ${ }^{3}$ Department of Hygiene Detection Center, Guangdong Provincial Key Laboratory of Tropical Disease Research, School of Public Health, Southern Medical University, Guangzhou 510515, China

${ }^{2}$ Department of Nutrition and Food Hygiene, Guangdong Provincial Key Laboratory of Tropical Disease Research, School of Public Health, Southern Medical University, Guangzhou 510515, China

Full list of author information is available at the end of the article
}

disease [4]. In 2015, 107.7 million children were obese worldwide; the overall prevalence was 5.0\% [5]. While in China, the prevalence had been dramatically increased for overweight and obesity (from 5.0\% to $19.2 \%$ during 1985 to 2010) [6], and especially for abdominal obesity (from $4.9 \%$ to $11.7 \%$ during 1993 to 2009) in children and adolescents aged < 18 years [7]. However, most of the previous studies used anthropometric indicators, like body mass index (BMI) or waist circumference (WC), for defining abdominal obesity, which might increase the possibility of misclassification since these indicators could not distinguish fat and lean mass precisely. Dual-energy X-ray absorptiometry (DXA) scans can provide direct and accurate measurement of the abdominal

(c) The Author(s). 2019 Open Access This article is distributed under the terms of the Creative Commons Attribution 4.0 International License (http://creativecommons.org/licenses/by/4.0/), which permits unrestricted use, distribution, and 
fat mass and distribution, and has been validated to be highly correlated with gold standards, like computed tomography [8], and magnetic resonance imaging [9]. However, until now, there is still lack of standardized cutoff value assessed by DXA to define abdominal obesity in Chinese children of early age.

Besides, most of the literature relies on BMI [10, 11], WC [12], waist-to-hip ratio (WHR) $[13,14]$ and waist-to-height ratio (WHtR) $[10,15,16]$, to estimate the abdominal fat distribution. While few studies show relationship between other anthropometric parameters, like chest circumference (CC) and hip circumference (HC), and abdominal obesity $[17,18]$. However, among a variety of anthropometric indicators, the most optimal one for predicting abdominal fat in Chinese children was still less clear.

Therefore, the objective of this study was to investigate the reference percentile curves for abdominal fat percentage (AFP) and to compare various anthropometric indicators (BMI, CC, WC, HC, WHR, and WHtR) in predicting abdominal obesity among children aged 6-9 years in China.

\section{Methods}

\section{Study population}

This cross-sectional study included 452-singleton birth children ( 255 boys and 197 girls) aged 6-9 years, who were recruited in urban Guangzhou, China, during December 2015 and March 2017. Two different ways were taken for the recruitment. One was by sending invitation letters with detailed criteria of inclusion and exclusion to several primary schools. 315 from a total of 1394 children responded and agreed to participate in the study. Another 206 children were enrolled through advertisements and referrals, bringing the total responding number to enroll to 521 . We restricted the study to healthy, full-term singleton children aged 6-9 years, and subjects with the following criteria were excluded: twins (12); born pretermly (25); exposure to related medical conditions (12) that might have interfered with growth, including digestive tract disease, kidney stones or nephritis, thyrotoxicosis, hepatitis, anaphylactoid purpura, metabolic bone disease; Core data unavailable (20); Therefore, a total of 452 children aged 6-9 years were included in the final analyses (Fig. 1). All subjects were invited for physical examination.

\section{Anthropometry}

Height and weight were measured with subjects in light clothing and shoes-off in standing position using a standard stadiometer and a Tanita MC-780A (Tanita Corporation, Tokyo, Japan) and accurate to $0.1 \mathrm{~cm}$ or $\mathrm{kg}$. $\mathrm{CC}, \mathrm{WC}$, and $\mathrm{HC}$ were measured using inelastic tape around the same anatomical sites. Height, CC, WC, HC were measured to the nearest $0.1 \mathrm{~cm}$ and weight to the

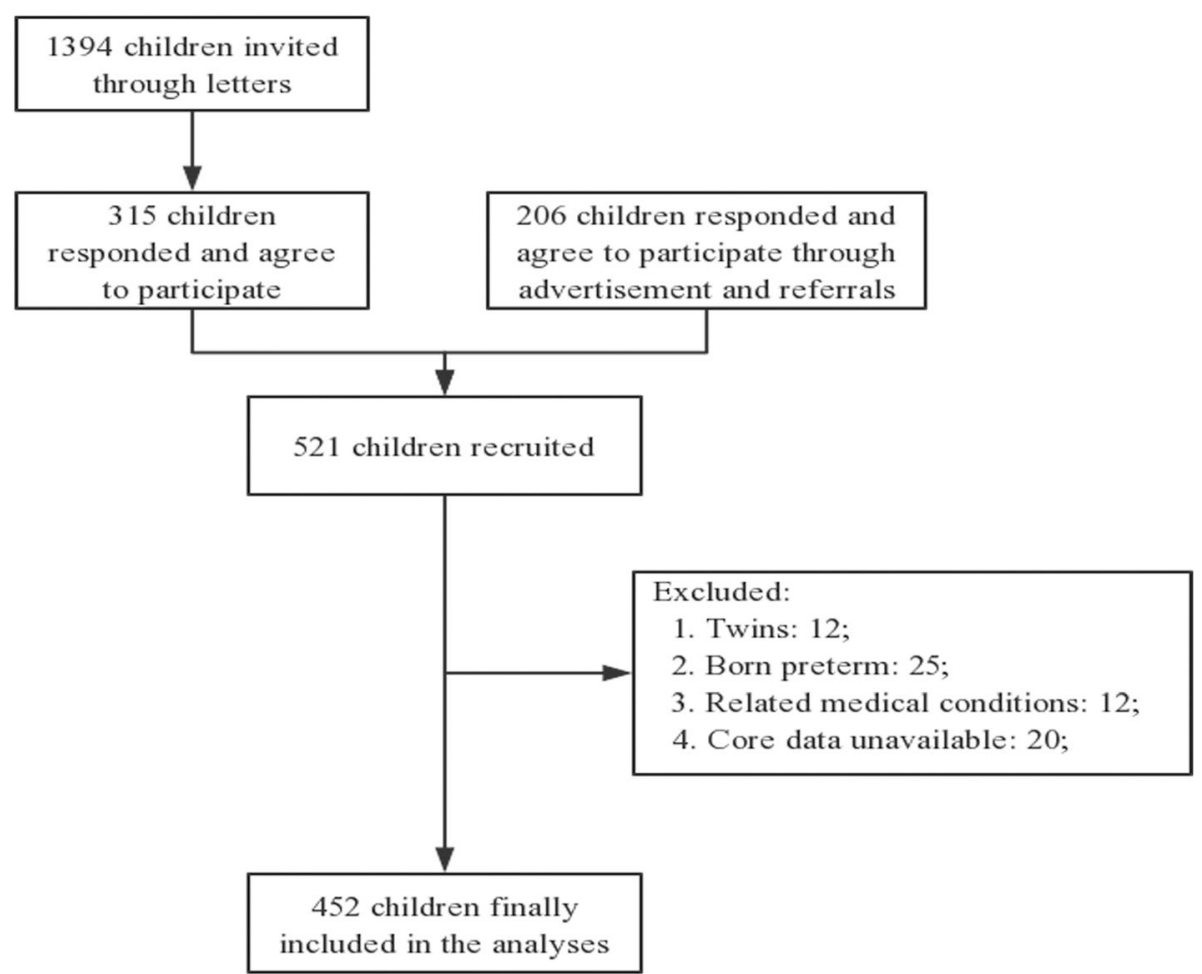

Fig. 1 Flow chart of study participants 
nearest $0.1 \mathrm{~kg}$. All these measurements were operated twice, or thrice if differences larger than $2 \mathrm{~cm}$ was found, and the averages were calculated. BMI was calculated as weight $(\mathrm{kg}) /$ height square $\left(\mathrm{m}^{2}\right)$. WHR was calculated as WC $(\mathrm{cm}) / \mathrm{HC}(\mathrm{cm})$. WHtR was calculated as WC $(\mathrm{cm}) /$ height $(\mathrm{cm})$.

\section{DXA scans}

Abdominal fat and lean mass were measured with a whole-body DXA scanner (Discovery W; Hologic Inc., Waltham, MA, USA), and analyzed by the same experienced technician. Subjects wore only light clothing without metal or objects with high density, and hold the standard posture with the guide of technician during the scan. For quality control, a spine phantom was used for daily correction before formal scans. The coefficient of variation between two consecutive measurements with repositioning among 35 random selected children in the same day was $2.54 \%$ for abdominal fat mass.

\section{Statistical analysis}

The data from boys and girls were analyzed separately and presented as Mean \pm standard deviation (SD) for the continuous variables and as frequencies and percentages for the categorical variables. Student's $t$ test was used to ascertain the significance of the difference in the continuous variables between boys and girls.

We calculated age- and sex-specific Z-scores and established age- and sex-specific reference values for AFP using LMSChartmaker 2.54 (Medical Research Council, London, UK). AFP values of each child were compared with corresponding, newly developed age- and sex-specific reference values to estimate $\mathrm{Z}$-scores and percentiles. Multivariate linear regression models were operated to examine the agreement between AFP and Z-scores for
BMI, CC, WC, HC, WHR and WHtR after adjusting for age (six pairs), stratified by sex. Area under the receiver-operating characteristic (ROC) curves were drawn with the help of MedCalc ${ }^{\circ}$ version 11.4.2.0 for Windows for estimating the screening of abdominal obesity (AFP $\geq 85$ th percentile) by using different anthropometric measures, stratified by sex. Values of area under curve (AUC) were estimated. Other analyses were operated using IBM SPSS 20.0 (Chicago, IL, USA) and a two-side $P$ value of $<0.05$ was considered statistically significant.

\section{Results}

\section{Characteristics of subjects}

The characteristics of subjects are shown in Table 1. The study included 255 (56.4\%) boys and 197 (43.6\%) girls. The mean ages were $7.97 \pm 0.91$ years for boys and $8.06 \pm$ 0.95 years for girls. The prevalence of abdominal obesity is $20.4 \%$ in boys and $16.8 \%$ in girls. Compared with girls, boys tend to have higher values of weight, BMI, CC, WC, WHR and WHtR $(P$ all $<0.05)$. No differences were found in average age, height, $\mathrm{HC}$ and AFP between boys and girls $(P>0.05)$.

\section{AFP percentile curves}

The reference percentile curves derived for AFP for boys and girls by age are illustrated in Figs. 2 and 3. Growth curves providing the 5 th, 10 th, 25 th, 50 th, 75 th, 85 th, 90 th, 95th centiles for AFP in boys and girls and equivalent percentile values are given in Table 2. The AFP of participants used to classify as abdominal obesity (AFP $\geq 85$ th percentile). The cutoff values of AFP in defining abdominal obesity among children aged 6, 7, 8, 9 years old are 24.80 , $30.29,31.58$, and $31.86 \%$, respectively in boys and 25.02 , $30.32,31.66$, and $31.79 \%$, respectively in girls.

Table 1 Selected characteristics of the study population

\begin{tabular}{|c|c|c|c|c|c|c|c|}
\hline \multirow[t]{2}{*}{ Variables } & \multicolumn{3}{|l|}{ Boys } & \multicolumn{3}{|l|}{ Girls } & \multirow{2}{*}{$\begin{array}{l}\text { Total } \\
\text { P-value }\end{array}$} \\
\hline & Obesity $(n=52)$ & Non-obesity $(n=203)$ & $\begin{array}{l}\text { Total } \\
(n=255)\end{array}$ & Obesity $(n=33)$ & Non-obesity $(n=164)$ & $\begin{array}{l}\text { Total } \\
(n=197)\end{array}$ & \\
\hline Age (years) & $8.17 \pm 1.03$ & $7.92 \pm 0.88$ & $7.97 \pm 0.91$ & $7.88 \pm 0.97$ & $8.10 \pm 0.95$ & $8.06 \pm 0.96$ & 0.285 \\
\hline Height (m) & $1.34 \pm 0.09^{* * *}$ & $1.28 \pm 0.08$ & $1.29 \pm 0.08$ & $1.30 \pm 0.08$ & $1.28 \pm 0.08$ & $1.28 \pm 0.08$ & 0.679 \\
\hline Weight (kg) & $37.1 \pm 10.4^{* * *}$ & $24.8 \pm 4.58$ & $27.3 \pm 7.93$ & $31.4 \pm 6.47^{* * *}$ & $24.1 \pm 4.43$ & $25.3 \pm 5.53$ & 0.002 \\
\hline $\mathrm{BMI}\left(\mathrm{kg} / \mathrm{m}^{2}\right)$ & $20.4 \pm 3.77^{* * *}$ & $15.1 \pm 1.66$ & $16.2 \pm 3.09$ & $18.3 \pm 2.18^{* * *}$ & $14.6 \pm 1.44$ & $15.2 \pm 2.10$ & $<0.001$ \\
\hline $\mathrm{CC}(\mathrm{cm})$ & $70.5 \pm 9.59^{* * *}$ & $59.1 \pm 4.05$ & $61.4 \pm 7.26$ & $64.8 \pm 5.85^{* * *}$ & $57.5 \pm 3.94$ & $58.7 \pm 5.10$ & $<0.001$ \\
\hline WC $(\mathrm{cm})$ & $68.8 \pm 10.5^{* * *}$ & $54.4 \pm 4.58$ & $57.4 \pm 8.52$ & $61.5 \pm 6.85^{* * *}$ & $52.8 \pm 4.16$ & $54.2 \pm 5.71$ & $<0.001$ \\
\hline $\mathrm{HC}(\mathrm{cm})$ & $77.1 \pm 9.18^{* * *}$ & $64.2 \pm 5.36$ & $66.8 \pm 8.17$ & $72.8 \pm 6.30^{* * *}$ & $64.2 \pm 5.16$ & $65.6 \pm 6.25$ & 0.07 \\
\hline WHR & $0.89 \pm 0.05^{* * *}$ & $0.85 \pm 0.04$ & $0.86 \pm 0.04$ & $0.84 \pm 0.05^{*}$ & $0.82 \pm 0.04$ & $0.83 \pm 0.05$ & $<0.001$ \\
\hline WHtR & $0.51 \pm 0.06^{* * *}$ & $0.42 \pm 0.03$ & $0.44 \pm 0.05$ & $0.47 \pm 0.04^{* * *}$ & $0.41 \pm 0.03$ & $0.42 \pm 0.04$ & $<0.001$ \\
\hline AFP (\%) & $35.5 \pm 5.07^{* * *}$ & $20.7 \pm 4.24$ & $23.7 \pm 7.43$ & $35.3 \pm 5.15^{* * *}$ & $22.8 \pm 4.39$ & $24.9 \pm 6.48$ & 0.08 \\
\hline
\end{tabular}

BMI Body Mass Index, CC Chest Circumference, HC Hip Circumference, WC Waist Circumference, WHR Waist-to-Hip Ratio, WHtR Waist-to-Height Ratio, AFP Abdominal fat percentage

atest for differences between boys and girls. ${ }^{*}: P<0.05 ;{ }^{* *}: P<0.01 ;{ }^{* * *}: P<0.001$ compared with the non-obesity groups 


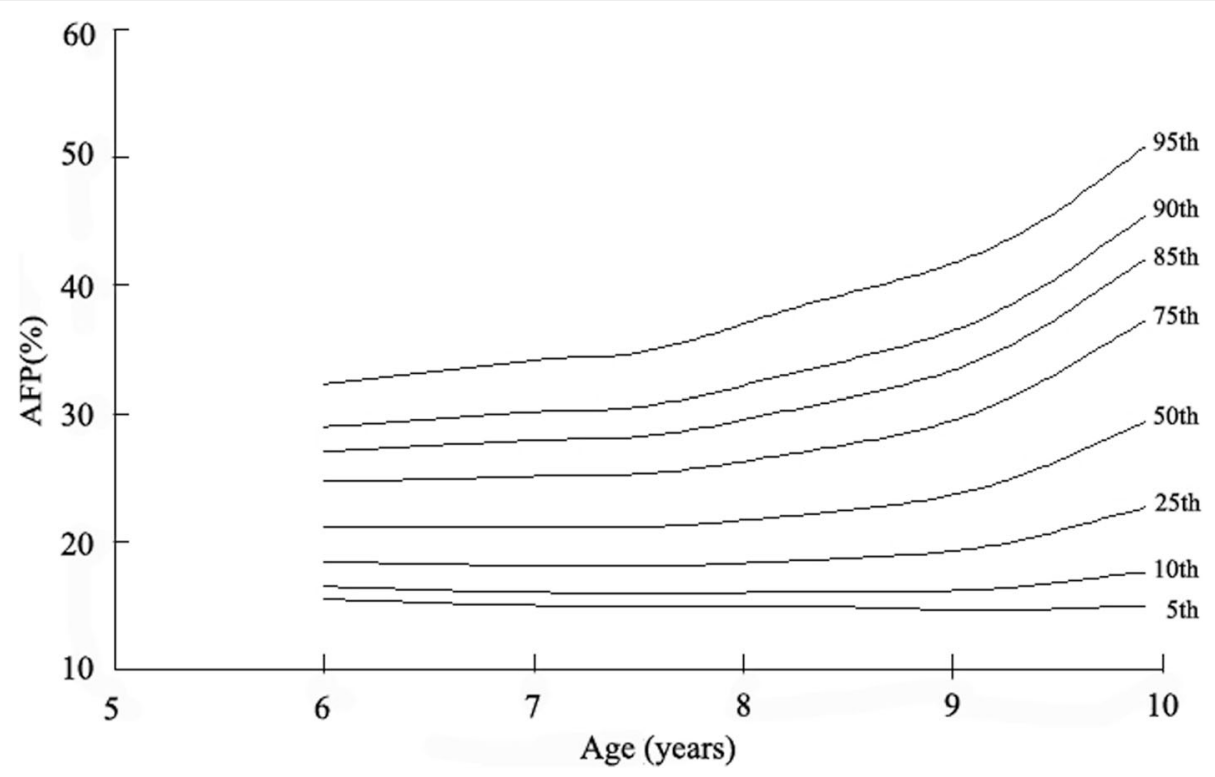

Fig. 2 Reference percentile curves of abdominal fat percentage for boys

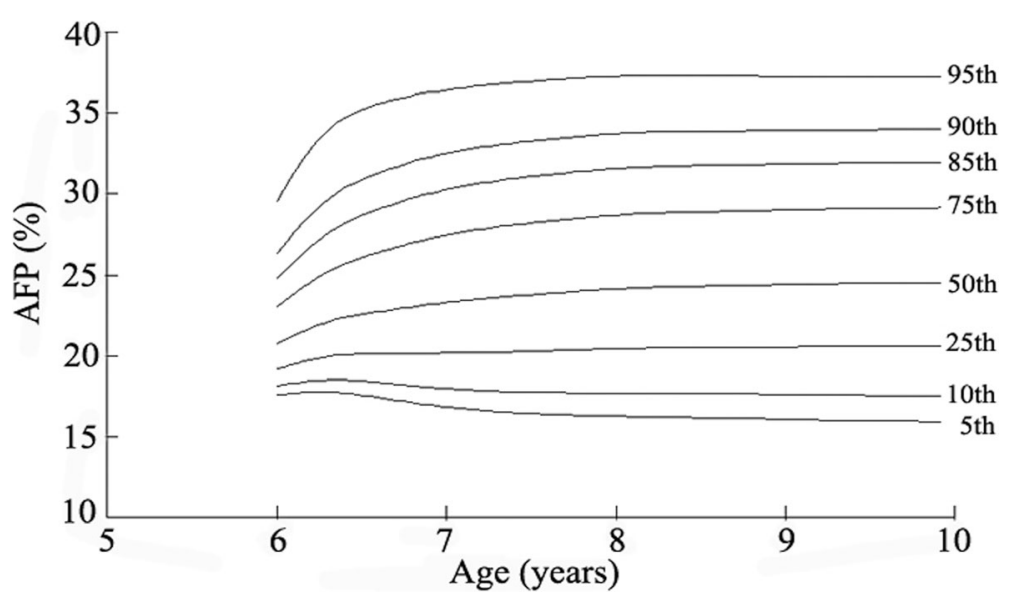

Fig. 3 Reference percentile curve of abdominal fat percentage for girls

Table 2 Smoothed percentiles for abdominal fat percentage among boys and girls aged 6-9 years

\begin{tabular}{|c|c|c|c|c|c|c|c|c|c|c|c|c|c|c|c|c|}
\hline \multirow{2}{*}{$\begin{array}{l}\text { Age } \\
\text { (years) }\end{array}$} & \multicolumn{8}{|c|}{ Percentile for boys (\%) } & \multicolumn{8}{|c|}{ Percentile for girls (\%) } \\
\hline & 5 th & 10th & 25 th & 50th & 75th & 85th & 90th & 95 th & 5 th & 10th & 25th & 50th & 75th & 85th & 90th & 95 th \\
\hline 6 & 17.57 & 18.12 & 19.20 & 20.78 & 23.06 & 24.80 & 26.34 & 29.57 & 17.86 & 18.38 & 19.42 & 20.96 & 23.23 & 25.02 & 26.67 & 30.38 \\
\hline 7 & 16.83 & 17.95 & 20.17 & 23.31 & 27.46 & 30.29 & 32.53 & 36.46 & 16.61 & 17.78 & 20.09 & 23.31 & 27.50 & 30.32 & 32.51 & 36.30 \\
\hline 8 & 16.27 & 17.69 & 20.44 & 24.13 & 28.69 & 31.58 & 33.75 & 37.30 & 16.35 & 17.75 & 20.45 & 24.13 & 28.72 & 31.66 & 33.88 & 37.56 \\
\hline 9 & 16.07 & 17.61 & 20.55 & 24.41 & 29.02 & 31.86 & 33.94 & 37.29 & 16.17 & 17.70 & 20.60 & 24.42 & 28.98 & 31.79 & 33.85 & 37.17 \\
\hline
\end{tabular}


Relationships between age-adjusted anthropometric indicators and AFP

Regression coefficient $(\beta)$ between age-adjusted anthropometric indicators and AFP were shown in Table 3. All anthropometric indicators were significantly and positively associated with AFP. BMI tend to provide the largest coefficients in girls but not in boys. Per one SD increase of relative anthropometric indicators, AFP increased by $3.173 \%$ to $6.632 \%$ in boys and $1.634 \%$ to $5.111 \%$ in girls.

\section{Performance of anthropometric measures}

AUC was used to evaluate the performance of each anthropometric indicator for the screening of abdominal obesity (AFP $\geq 85$ th) by sex. As shown in Table 4, BMI and WHtR exhibited the largest AUC in both boys (AUC $=0.913$ and 0.922) and girls $(\mathrm{AUC}=0.925$ and 0.886). For other indicators (CC, WC, HC, WHR), AUC values ranged from 0.744 to 0.898 in boys and from 0.605 to 0.869 in girls. Significant higher AUC were found for BMI compared to other indicators expect for WHtR in girls $(P<0.01)$, and $C C$ and WHR, but not WC, HC, WHtR in boys. For both boys and girls, WHR performed were poorest in predicting abdominal obesity by providing least AUC values ( 0.744 in boys and 0.605 in girls), which were significantly lesser than those observed for BMI or WHtR $(P<0.001)$.

\section{Discussion}

According to our knowledge, this is the first study to develop age- and gender-specific reference percentiles for AFP measured by DXA for Chinese children. Besides, we further found that BMI and WHtR, compared with other indicators, performed optimally in predicting abdominal obesity in Chinese girls and boys, respectively.

Former evidence had indicated that obesity; especially abdominal obesity in early childhood might increase the risk of later chronic diseases [4-7]. It is important to

Table 3 Relationships of age-adjusted physical indicators for assessing abdominal fat percentage in boys and girls

\begin{tabular}{|c|c|c|c|c|c|c|}
\hline \multirow[t]{2}{*}{ Variables } & \multicolumn{3}{|l|}{ Boys } & \multicolumn{3}{|l|}{ Girls } \\
\hline & $\overline{\beta^{a}(\%)}$ & $\beta^{\mathrm{b}}(\%)$ & $P$ value & $\overline{\beta^{a}(\%)}$ & $\beta^{\mathrm{b}}(\%)$ & $P$ value \\
\hline BMl & 6.209 & 0.835 & $<0.001$ & 5.111 & 0.789 & $<0.001$ \\
\hline CC & 6.389 & 0.860 & $<0.001$ & 4.781 & 0.738 & $<0.001$ \\
\hline WC & 6.379 & 0.858 & $<0.001$ & 4.854 & 0.749 & $<0.001$ \\
\hline $\mathrm{HC}$ & 6.632 & 0.892 & $<0.001$ & 4.994 & 0.770 & $<0.001$ \\
\hline WHR & 3.173 & 0.427 & $<0.001$ & 1.634 & 0.252 & 0.001 \\
\hline $\mathrm{WHtR}$ & 5.845 & 0.786 & $<0.001$ & 4.861 & 0.750 & $<0.001$ \\
\hline
\end{tabular}

Per one standard deviance increase of anthropometric indicators BMI Body Mass Index, CC Chest Circumference, HC Hip Circumference, WC Waist Circumference, WHR Waist-to-Hip Ratio, WHtR Waist-to-Height Ratio ${ }^{a}$ : unstandardized regression coefficients . ${ }^{\text {b: }}$ standardized regression coefficients explore the reference values of the abdominal obesity measured by more precisely methods, like DXA. However, the corresponding reference values had not been established in Chinese children before. Using the available data, we filled the gap on this field. Besides, considering attenuated time and economic expenditure, it would be of great utility value to investigate the most optimal anthropometric indicators correlated with abdominal obesity measured by DXA, when applied in large epidemiology surveys.

In our study, we observed that BMI tend to be the optimal indicator of abdominal obesity in young Chinese children aged 6-9 years, especially in girls. In consistent with our results, several studies showed BMI was highly correlated to abdominal fat. Dencker et al. found strong correlation between BMI and abdominal fat mass in Swedish children $(r=0.93-0.95)$ [19]. Moreover, based on Japanese children population, BMI was also recommended as a screening tool to identify abdominal adiposity. The researchers suggested that the optimal cut-off values for BMI were $20 \mathrm{~kg} / \mathrm{m}^{2}$ for boys (sensitivity: 100\%, specificity: $90 \%$ ) and $19 \mathrm{~kg} / \mathrm{m}^{2}$ for girls (sensitivity: 100\%, specificity: 90\%) [10]. However, there are other studies that claim BMI might give less indication of fat distribution $[6,20,21]$, and might be interfered by fat free mass [22]. Accordingly, few studies suggested that the measurement of BMI was needed in addition to WC [6] or WHtR [19]. Former evidence indicated WC [10, 23-26] and WHtR [10, 20] as good indicators in predicting abdominal obesity in children, however, BMI was more superior compared with WC in girls and not different with WHtR in predicting childhood abdominal obesity in our study. The divergent conclusions might be sources from the difference of population studied. Children in China and Japan tend to be with lower BMI or obesity degree than those from the western countries. Therefore, relative less fat is deposited at the abdomen, and then might attenuate the utility of WC and related indicators, especially in children. More studies were needed for better illustration of the problem.

WHR was found as a poor predictor of childhood abdominal obesity in our study, the results were consistent with several other studies [23, 25] . Taylor et al. showed that WHR was poorly associated with central adiposity [25]. The use of WHR to assess abdominal obesity in children might not be appropriate because this ratio is highly age dependent [27]. Our results together with former evidence, suggested that WHR might be of less value in predicting abdominal obesity in children.

One of the strengths of this study was that we provided the first reference data of AFP based on Chinese children aged 6-9 years. Additionally, by comparing several anthropometric indicators, we found that BMI and WHtR tended 
Table 4 Comparison of the Receivers Operator Characteristic curves for various anthropometric indices in predicting abdominal obesity

\begin{tabular}{|c|c|c|c|c|c|c|c|}
\hline \multicolumn{2}{|c|}{ Variables } & \multirow{2}{*}{$\frac{\text { AUC }}{0.913}$} & \multirow{2}{*}{$\frac{95 \% \mathrm{Cl}}{0.872,0.945}$} & \multirow{2}{*}{$\begin{array}{l}\text { Sensitivity (\%) } \\
73.1\end{array}$} & \multirow{2}{*}{$\begin{array}{l}\text { Specificity (\%) } \\
95.1\end{array}$} & \multirow{2}{*}{$\frac{P \text { value }^{a}}{-}$} & \multirow{2}{*}{$\frac{P \text { value }^{\mathrm{b}}}{0.542}$} \\
\hline Boys & BMI & & & & & & \\
\hline & CC & 0.870 & $0.822,0.908$ & 76.9 & 85.2 & 0.017 & 0.041 \\
\hline & WC & 0.898 & $0.854,0.932$ & 78.9 & 87.2 & 0.307 & 0.247 \\
\hline & $\mathrm{HC}$ & 0.882 & $0.836,0.919$ & 69.2 & 92.6 & 0.057 & 0.114 \\
\hline & WHR & 0.744 & $0.686,0.796$ & 59.6 & 76.4 & $<0.001$ & $<0.001$ \\
\hline & WHtR & 0.922 & $0.882,0.952$ & 80.8 & 88.7 & 0.542 & - \\
\hline \multirow[t]{6}{*}{ Girls } & BMI & 0.925 & $0.879,0.958$ & 90.9 & 87.6 & - & 0.217 \\
\hline & CC & 0.852 & $0.794,0.898$ & 72.7 & 86.0 & 0.007 & 0.472 \\
\hline & WC & 0.863 & $0.807,0.908$ & 69.7 & 88.4 & 0.006 & 0.431 \\
\hline & $\mathrm{HC}$ & 0.869 & $0.814,0.913$ & 87.9 & 76.2 & 0.006 & 0.712 \\
\hline & WHR & 0.605 & $0.533,0.674$ & 36.4 & 86.6 & $<0.001$ & $<0.001$ \\
\hline & WHtR & 0.886 & $0.833,0.926$ & 81.8 & 80.5 & 0.217 & - \\
\hline
\end{tabular}

BMI Body Mass Index, CC Chest Circumference, HC Hip Circumference, WC Waist Circumference, WHR Waist-to-Hip Ratio, WHtR Waist-to-Height Ratio

a:Compared with BMI. ${ }^{\text {b: }}$ Compared with WHtR

to perform optimally in predicting childhood abdominal obesity, which might provide more specific guidance for large epidemiology surveys focus on childhood obesity. There were also several limitations in our study. Firstly, due to the absence of standard cut-off for AFP in Chinese children, we used the $85 \%$ value as a cut-off to determine abdominal obesity. However, this cut-off value might be likely to differ in different populations. Secondly, with the cross-sectional design, we fail to investigate the best anthropometric indicators in predicting the dynamic trajectory of abdominal obesity in children. Thirdly, the study was based on a relatively small sample of children with a limited age range; more studies with large samples and wider age range were needed to reexamine our results. Lastly, the measurement of neck circumference and sexual development assessment were not performed in the study. Therefore, we could not perform further analyses on these fields, which were encouraged to be involved in further studies.

\section{Conclusions}

We present the first reference data for AFP in Chinese children aged 6-9 years. Compared with other anthropometric indicators, BMI and WHtR tend to perform optimally in predicting childhood abdominal obesity.

\section{Abbreviations}

AFP: Abdominal fat percentage; AUC: Area under curve; BMI: Body mass index; CC: Chest circumference; DXA: Dual-energy X-ray absorptiometry; HC: Hip circumference; SD: Standard deviation; WC: Waist circumference; WHR: Waist-to-hip ratio; WHtR: Waist-to-height ratio

\section{Acknowledgements}

The authors would like to thank all research members involved in the data collection of the study.
Funding

This work was funded by National Natural Science Foundation of China (No.81502798), Natural Science Foundation of Guangdong Province, China (No.2015A030310399), and The Maternal and Children Nutrition and Care Fund of Biostime (No.BINCMYF15006). The funding sponsors had no role in the design of the study; in the collection, analyses, or interpretation of data; in the writing of the manuscript, and in the decision to publish the results.

\section{Availability of data and materials}

The dataset supporting the findings of the study is available from the corresponding author on request.

\section{Authors' contributions}

GDC and HCY analyzed the data and wrote the paper. YTH contributed to the data collection. SS revised the manuscript; JW, YL, and YHW were parts of the data collection team; JLP: supervised the study and revised the manuscript. ZQZ designed the project, supervised the study and revised the manuscript. All authors have read and approved the manuscript.

\section{Ethics approval and consent to participate}

A written consent was approved by each participant through his or her parent or legal guardian before enrollment. Informed consent was also obtained from each subject (or their parents/guardian) to analyse and publish his or her data. The study was conducted in accordance with the Declaration of Helsinki and was approved by the ethics committee of the School of Public Health at Sun Yat-sen University (201549).

\section{Consent for publication}

Not applicable.

\section{Competing interests}

The authors declare that they have no competing interests.

\section{Publisher's Note}

Springer Nature remains neutral with regard to jurisdictional claims in published maps and institutional affiliations.

\section{Author details}

${ }^{1}$ Foshan Institute of Fetal Medicine, Department of Obstetrics, Southern Medical University Affiliated Maternal \& Child Health Hospital of Foshan, Foshan 528000, Guangdong, China. ${ }^{2}$ Department of Nutrition and Food 
Hygiene, Guangdong Provincial Key Laboratory of Tropical Disease Research, School of Public Health, Southern Medical University, Guangzhou 510515, China. ${ }^{3}$ Department of Hygiene Detection Center, Guangdong Provincial Key Laboratory of Tropical Disease Research, School of Public Health, Southern Medical University, Guangzhou 510515, China.

Received: 15 November 2018 Accepted: 10 April 2019

Published online: 24 April 2019

\section{References}

1. Ng M, Fleming T, Robinson M, Thomson B, Graetz N, Margono C, Mullany EC, Biryukov S, Abbafati C, Abera SF, et al. Global, regional, and national prevalence of overweight and obesity in children and adults during 19802013: a systematic analysis for the global burden of disease study 2013. Lancet. 2014;384(9945):766-81. https://doi.org/10.1016/S01406736(14)60460-8

2. Liang $Y$, Hou D, Zhao $X$, Wang $L$, Hu $Y$, Liu J, Cheng $H$, Yang $P$, Shan $X$, Yan $Y$, et al. Childhood obesity affects adult metabolic syndrome and diabetes. Endocrine. 2015;50(1):87-92. https://doi.org/10.1111/j.2047-6310. 2012.00066.x.

3. Bhupathiraju SN, Hu FB. Epidemiology of obesity and diabetes and their cardiovascular complications. Circ Res. 2016;118(11):1723-35. https://doi.org/ 10.1161/CIRCRESAHA.115.306825.

4. Piche ME, Poirier P, Lemieux I, Despres JP. Overview of epidemiology and contribution of obesity and body fat distribution to cardiovascular disease: an update. Prog Cardiovasc Dis. 2018;61(2):103-13. https://doi.org/10.1016/j. pcad.2018.06.004.

5. Afshin A, Forouzanfar MH, Reitsma MB, Sur P, Estep K, Lee A, Marczak L, Mokdad AH, Moradi-Lakeh M, Naghavi M, et al. Health effects of overweight and obesity in 195 countries over 25 years. N Engl J Med. 2017;377(1):13-27. https://doi.org/10.1056/NEJMoa1614362.

6. Sun $H, M a Y$, Han D, Pan CW, Prevalence $X Y$. Trends in obesity among China's children and adolescents, 1985-2010. PLoS One. 2014;9(8):e105469. https://doi.org/10.1371/journal.pone.0105469.

7. Liang YJ, Xi B, Song AQ, Liu JX, Mi J. Trends in general and abdominal obesity among Chinese children and adolescents 1993-2009. Pediatr Obes. 2012:7(5):355. https://doi.org/10.1111/j.2047-6310.2012.00066.x

8. Micklesfield LK, Goedecke JH, Punyanitya M, Wilson KE, Kelly TL. Dual-energy $X$-ray performs as well as clinical computed tomography for the measurement of visceral fat. Obesity (Silver Spring). 2012;20(5):1109-14. https://doi.org/10.1038/oby.2011.367.

9. Taylor AE, Kuper H, Varma RD, Wells JC, Bell JD, K VR, Kulkarni B, Kinra S, Timpson NJ, Ebrahim S, et al. Validation of dual energy X-ray absorptiometry measures of abdominal fat by comparison with magnetic resonance imaging in an Indian population. PLoS One. 2012;7(12):e51042. https://doi. org/10.1371/journal.pone.0051042.

10. Fujita $Y$, Kouda K, Nakamura H, Iki M. Cut-off values of body mass index, waist circumference, and waist-to-height ratio to identify excess abdominal fat: population-based screening of Japanese schoolchildren. J Epidemiol. 2011;21(3):191-6. https://doi.org/10.2188/jea.JE20100116.

11. Bacopoulou F, Efthymiou V, Landis G, Rentoumis A, Chrousos GP. Waist circumference, waist-to-hip ratio and waist-to-height ratio reference percentiles for abdominal obesity among Greek adolescents. BMC Pediatr. 2015:15:50. https://doi.org/10.1186/s12887-015-0366-z.

12. Kim SG, Ko K, Hwang IC, Suh HS, Kay S, Caterson I, Kim KK. Relationship between indices of obesity obtained by anthropometry and dual-energy $X$ ray absorptiometry: the fourth and fifth Korea National Health and nutrition examination survey (KNHANES IV and V, 2008-2011). Obes Res Clin Pract. 2015;9(5):487-98. https://doi.org/10.1016/j.orcp.2014.11.002.

13. Man RE, Sabanayagam C, Chiang PP, Li LJ, Noonan JE, Wang JJ, Wong TY, Cheung GC, Tan GS, Lamoureux EL. Differential Association of Generalized and Abdominal Obesity with Diabetic Retinopathy in Asian patients with type 2 diabetes. JAMA Ophthalmol. 2016;134(3):251. https://doi.org/10.1001/ jamaophthalmol.2015.5103.

14. Emdin CA, Khera AV, Natarajan P, Klarin D, Zekavat SM, Hsiao AJ, Kathiresan S. Genetic Association of Waist-to-hip Ratio with Cardiometabolic Traits, type 2 diabetes, and coronary heart disease. JAMA. 2017;317(6):626-34. https://doi.org/10.1001/jama.2016.21042.

15. Zhang $Y$, Zhao J, Chu Z, Tan $\mathrm{H}$. Prevalence and regional disparities in abdominal obesity among children and adolescents in Shandong,
China, surveyed in 2010. Ann Nutr Metab. 2014;64(2):137. https://doi. org/10.1159/000365013.

16. Ochiai H, Shirasawa T, Nishimura R, Nanri H, Ohtsu T, Hoshino H, Tajima N Kokaze A. Waist-to-height ratio is more closely associated with alanine aminotransferase levels than body mass index and waist circumference among population-based children: a cross-sectional study in Japan. BMC Pediatr. 2015;15:59. https://doi.org/10.1186/s12887-015-0378-8.

17. Rodrigues dOPF, Cremonezi JC, Díezgarcía RW, Salles MC, García CP. The use of body circumferences for the prediction of intra-abdominal fat in obese women with polycystic ovary syndrome. Nutr Hosp. 2012;27(5):16626. https://doi.org/10.3305/nh.2012.27.5.5933.

18. Darbandi M, Darbandi S, Owji AA, Mokarram P, Mobarhan MG, Fardaei M, Zhao B, Abdi H, Nematy M, Safarian M. Auricular or body acupuncture: which one is more effective in reducing abdominal fat mass in Iranian men with obesity: a randomized clinical trial. J Diabetes Metab Disord. 2014;13(1): 92. https://doi.org/10.1186/s40200-014-0092-3.

19. Dencker M, Thorsson O, Linden C, Wollmer P, Andersen LB, Karlsson MK. BMI and objectively measured body fat and body fat distribution in prepubertal children. Clin Physiol Funct Imaging. 2007;27(1):12-6. https:// doi.org/10.1111/j.1475-097X.2007.00709.X.

20. Karlsson AK, Kullberg J, Stokland E, Allvin K, Gronowitz E, Svensson PA, Dahlgren J. Measurements of total and regional body composition in preschool children: a comparison of MRI, DXA, and anthropometric data. Obesity (Silver Spring). 2013;21(5):1018-24. https://doi.org/10.1002/oby.20205.

21. Vanderwall C, Randall Clark R, Eickhoff J, Carrel AL. BMI is a poor predictor of adiposity in young overweight and obese children. BMC Pediatr. 2017;17(1): 135. https://doi.org/10.1186/s12887-017-0891-z.

22. Freedman DS, Wang J, Maynard LM, Thornton JC, Mei Z, Pierson RN, Dietz WH, Horlick M. Relation of BMI to fat and fat-free mass among children and adolescents. Int J Obes. 2004;29(1):1-8. https://doi.org/10.1038/sj.ijo.0802735.

23. Castro-Pinero J, Artero EG, Espana-Romero V, Ortega FB, Sjostrom M, Suni J, Ruiz JR. Criterion-related validity of field-based fitness tests in youth: a systematic review. Br J Sports Med. 2010;44(13):934-43. https://doi.org/10. 1136/bjsm.2009.058321.

24. Brambilla P, Bedogni G, Moreno LA, Goran MI, Gutin B, Fox KR, Peters DM, Barbeau P, De SM, Pietrobelli A. Crossvalidation of anthropometry against magnetic resonance imaging for the assessment of visceral and subcutaneous adipose tissue in children. Int J Obes. 2006;30(1):23. https:// doi.org/10.1038/sj.ijo.0803163.

25. Taylor RW, Jones IE, Williams SM, Goulding A. Evaluation of waist circumference, waist-to-hip ratio, and the conicity index as screening tools for high trunk fat mass, as measured by dual-energy X-ray absorptiometry, in children aged 3-19 y. Am J Clin Nutr. 2000;72(2):490. https://doi.org/10. 1093/ajen/72.2.490.

26. Daniels SR, Khoury PR, Morrison JA. Utility of different measures of body fat distribution in children and adolescents. Am J Epidemiol. 2000;152(12):1179-84.

27. Power C, Lake JK, Cole TJ. Measurement and long-term health risks of child and adolescent fatness. Int J Obes Relat Metab Disord. 1997:21(7):507-26.

Ready to submit your research? Choose BMC and benefit from:

- fast, convenient online submission

- thorough peer review by experienced researchers in your field

- rapid publication on acceptance

- support for research data, including large and complex data types

- gold Open Access which fosters wider collaboration and increased citations

- maximum visibility for your research: over $100 \mathrm{M}$ website views per year

At BMC, research is always in progress.

Learn more biomedcentral.com/submission 